\title{
ESTUDO DA INFLUÊNCIA DO DIÂMETRO DO ORIFÍCIO PILOTO NA RESISTÊNCIA AO ARRANCAMENTO DO PARAFUSO PEDICULAR
}

\author{
THE INFLUENCE OF PILOT HOLE DIAMETER ON THE SCREW PULLOUT RESISTANCE
}

\author{
José Roberto Benites Vendrame ${ }^{1}$, Antônio Carlos Shimano², Frank Kandziora ${ }^{3}$, Helton luiz Aparecido Defino 4
}

\section{RESUMO}

A influência do diâmetro do orifício piloto em relação ao diâmetro interno do parafuso na resistência ao arrancamento do parafuso pedicular foi o objetivo do estudo. Foram utilizados parafusos de 5, 6 e $7 \mathrm{~mm}$ do sistema USS de fixação vertebral, os quais foram inseridos nos corpos de prova de madeira, poliuretana e osso. O orifício piloto para a inserção do parafuso foi realizado com brocas de diâmetro inferior, igual e superior ao diâmetro interno do parafuso. Ensaios mecânicos de arrancamento foram realizados em máquina universal de teste. Nos corpos de prova de madeira, poliuretana e osso a realização do orifício piloto com brocas de diâmetro maior que o diâmetro interno do parafuso produziu diminuição da força máxima de arrancamento dos implantes nos ensaios de arrancamento, tendo sido observada diferença estatística. O diâmetro da perfuração do orifício piloto em relação ao diâmetro interno do parafuso exerce influência na resistência ao arrancamento do implante, tendo sido observado aumento da resistência ao arrancamento com a utilização de brocas de diâmetro menor que o diâmetro interno e redução da resistência ao arrancamento com a utilização de brocas com diâmetro maior que o diâmetro interno do parafuso.

Descritores: Coluna vertebral; Parafusos ósseos; Biomecânica.

\section{SUMMARY}

The influence of the diameter of the pilot hole compared to the inner diameter of the screw on the pull-out resistance of a pedicular screw was studied. 5-, 6-, and 7-mm USS system screws for vertebral fixation were inserted into wood, polyurethane and bone test bodies. The pilot hole for screw insertion was drilled with burrs of smaller, equal or wider diameter than the inner diameter of the screw. Mechanical pull-out assays were performed using a universal testing machine. In the wood, polyurethane and bone test bodies, a pilot hole drilled with burrs of a wider diameter than the inner diameter of the screw produced reduced maximum pull-out strength on the implants, with statistical significance. The drilling diameter of the pilot hole compared to the inner diameter of the screw influences implant pull-out strength, with an increased pull-out resistance being observed with the use of smaller diameter burrs as compared to the inner diameter, and a reduction of pull-out resistance being observed with the use of burrs of a wider diameter than the inner diameter of the screw.

Keywords: Spine; Bone screws; Biomechanics.
Citação: Vendrame JRB, Shimano AC, Kandziora F, Defino HLA. Estudo da influência do diâmetro do orifício piloto na resistência ao arrancamento do parafuso pedicular. Acta Ortop Bras. [periódico na Internet]. 2008; 16(2):69-73. Disponíve em URL: http://www.scielo.br/aob.
Citation: Vendrame JRB, Shimano AC, Kandziora F, Defino HLA. The influence of pilot hole diameter on the screw pullout resistance. Acta Ortop Bras. [serial on the Internet]. 2008; 16(2):69-73. Available from URL: http://www.scielo.br/aob.

\section{INTRODUÇÃO}

Os parafusos pediculares tem sido muito utilizados nos sistemas de fixação vertebral devido às suas vantagens biomecânicas em relação aos demais implantes, e têm sido empregados no tratamento das lesões traumáticas, tumorais, degenerativas, e deformidades da coluna vertebral| ${ }^{(1,2)}$.

Na constelação biomecânica dos sistemas de fixação vertebral a ancoragem dos implantes no tecido ósseo é a base ou o alicerce de qualquer sistema de fixação vertebral, não importando a sua indicação ou função biomecânica ${ }^{(2-4)}$.

A aplicação dos parafusos pediculares na coluna vertebral requer o preparo da estrutura anatômica da vértebra em que o implante será colocado, que é denominado de orifício piloto . O orifício piloto pode ser realizado por meio de brocas, sondas ou curetas; e o seu diâmetro deve ser considerado em relação ao diâmetro do implante a ser utilizado. O diâmetro do orifício é de grande importância na utilização dos parafusos pediculares, pois pode interferir diretamente na sustentação do sistema de fixação vertebral e apresentar repercussões sobre o resultado final do tratamento.

O objetivo do trabalho foi avaliar a possível influência do diâmetro da perfuração do orifício piloto em relação ao diâmetro interno do parafuso, sobre a resistência ao arrancamento dos parafusos pediculares

\section{MATERIAL E MÉTODO}

Foram utilizados no estudo corpos de prova de poliuretana, madeira e osso bovino. Os corpos de prova de poliuretana possuíam $27 \mathrm{~mm}$ de espessura, os de madeira $13 \mathrm{~mm}$ e os de osso bovino $17 \mathrm{~mm}$

Trabalho realizado no Departamento de Biomecânica, Medicina e Reabilitação do Aparelho Locomotor da Faculdade de Medicina de Ribeirão Preto da Universidade de São Paulo. Trabalho realizado com o apoio da FAPES e CAPES-PROBRAL.

Endereço para correspondência: Helton L. A. Defino - Departamento de Biomecânica, Medicina e Reabilitação do Aparelho Locomotor da Faculdade de Medicina de Ribeirão Preto da Universidade de São Paulo Avenida Bandeirantes, 3900 - 11 o and - Campus Universitário - Ribeirão Preto/São Paulo - hladefin@fmrp.usp.br

1. Pós-graduando do Departamento de Biomecânica, Medicina e Reabilitação do Aparelho Locomotor da Faculdade de Medicina de Ribeirão Preto da Universidade de São Paulo. 2. Professor, Doutor do Departamento de Biomecânica, Medicina e Reabilitaçáo do Aparelho Locomotor da Faculdade de Medicina de Ribeirão Preto da Universidade de São Paulo

3. Chefe do Setor de Cirurgia da Coluna Vertebral do Departamento de Doenças do Aparelho Locomotor - Hospital Charitté - Berlin Head of Spine Center

4. Professor Titular do Departamento de Biomecânica, Medicina e Reabilitação do Aparelho Locomotor da Faculdade de Medicina de Ribeirão Preto da Universidade de São Paulo. Trabalho recebido em 21/08/07 aprovado em 18/12/07 
de espessura. O corpo de prova de osso bovino era constituído da parte metafisária central e distal do fêmur, que era preparada com o auxílio de serra, removendo-se o osso cortical externo e confeccionando-se segmentos de osso esponjoso de $17 \mathrm{~mm}$ de espessura.

Os implantes utilizados no estudo foram os parafusos pediculares de 5, 6 e 7 mm de diâmetro do sistema USS (Synthes) (Figura 1). Os parafusos foram implantados nos respectivos corpos de prova após a realização do orifício piloto utilizando-se brocas de diferentes diâmetros em relação ao diâmetro interno do parafuso. Desse modo para os ensaios realizados com os parafusos de $5 \mathrm{~mm}$ de diâmetro externo e que possuem $3,8 \mathrm{~mm}$ de diâmetro interno, foram realizadas perfurações de 3,2; 3,8; 4,0 e 4,8mm de diâmetro. Os parafusos de $6,0 \mathrm{~mm}$ de diâmetro possuem diâmetro interno de 4,8mm e foram realizadas perfurações de 4,0; 4,5; 4,8; 5,0 e $5,5 \mathrm{~mm}$ de diâmetro. Os parafusos de 7,0 mm de diâmetro possuem diâmetro interno de 4,8mm e foram realizadas perfurações de 4,0; 4,8; 5,0; 5,5; 6,0 e 6,5mm de diâmetro.

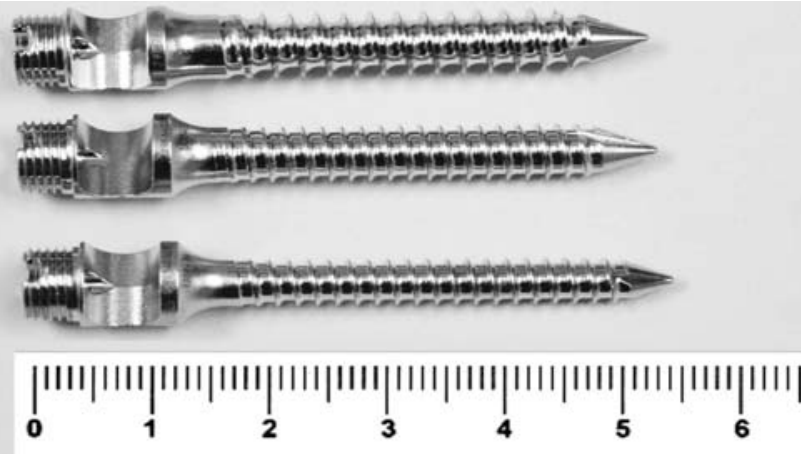

Figura 1 - Parafusos utilizados no estudo. De cima para baixo observar o parafuso de $5 \mathrm{~mm}(3,8 \mathrm{~mm}$ de diâmetro interno), o parafuso de $6 \mathrm{~mm}(4,8 \mathrm{~mm}$ de diâmetro interno) e o parafuso de $7 \mathrm{~mm}$ (4,8mm de diâmetro interno).

Após a realização do orifício no corpo de prova o parafuso era introduzido, transfixando o corpo de prova e deixando $1 \mathrm{~cm}$ da sua extremidade distal exposta. Desse modo o número de rosca dos parafusos contidos nos corpos de prova era constante, e a extremidade distal exposta do parafuso era utilizada para a aplicação da força nos ensaios mecânicos de resistência ao arrancamento. Os grupos experimentais foram formados de acordo com o diâmetro do parafuso utilizado (5,0; 6,0 e 7,0mm), o corpo de prova utilizado e o diâmetro do orifício piloto. Para os parafusos de 5 e $7 \mathrm{~mm}$ foram utilizados corpos de prova de madeira e poliuretana. Para os parafusos de $6 \mathrm{~mm}$ foram utilizados corpos de prova de madeira, poliuretana e osso bovino.

Foram realizados 10 ensaios mecânicos para os grupos experimentais dos corpos de prova de poliuretana e 15 ensaios mecânicos para os grupos experimentais dos corpos de prova de osso bovino. Os ensaios mecânicos foram realizados em máquina universal de ensaio (modelo EMIC ${ }^{\circledR}$, Brasil), ligada a computador e célula de carga de 200 Kgf. A resistência dos implantes ao arrancamento foi avaliada por meio da aplicação de carga axial ao longo do eixo do parafuso, aplicada sobre a extremidade distal (ponta) do parafuso, e mensuração do valor necessário para o deslocamento do implante.

Os resultados obtidos foram comparados por meio de estudo estatístico, tendo sido utilizado o teste de análise de variância (ANOVA) para a detecção da diferença estatística entre os grupos experimentais e o teste "pos hoc de Bonferroni" para a determinação específica da diferença entre os parâmetros estudados. Foi estabelecido o nível de significância de $5 \%(p \leq 0,05)$.

\section{RESULTADOS}

Os resultados serão apresentados considerando-se o diâmetro do parafuso utilizado e a natureza do corpo de prova.

Os resultados relacionados com a utilização do parafuso de 5,0mm nos corpos de prova de madeira (Tabela 1 e Figura 2). Foi observado que a média dos valores da força máxima de arrancamento diminuía à medida que o diâmetro da perfuração aumentava. Considerandose o diâmetro da perfuração correspondente ao diâmetro interno do parafuso $(3,8 \mathrm{~mm})$, foi observado aumento da força de arrancamento com a utilização da broca de 3,2mm, porém não houve diferença estatística significativa. Os valores observados com a utilização das brocas com diâmetros maiores que o diâmetro interno do parafuso (3,8mm) apresentaram diminuição dos valores da força máxima de arrancamento, e foi observada diferença estatística significativa entre os valores. Não foi possível realizar os ensaios mecânicos com o grupo de implantes nos quais o diâmetro da perfuração foi de $4,8 \mathrm{~mm}$. Nesse grupo os implantes a aplicação da pré-carga já produzia o arrancamento dos implantes do corpo de prova.

\begin{tabular}{c|c|c|c|c}
\hline $\begin{array}{c}\text { Diâmetro } \\
\text { da broca } \\
(\mathbf{m m})\end{array}$ & $\begin{array}{c}\text { Força } \\
\text { Máxima } \\
\text { média (N) }\end{array}$ & $\begin{array}{c}\text { Desvio } \\
\text { padrão }\end{array}$ & $\begin{array}{c}\text { Coeficiente } \\
\text { de variação } \\
(\%)\end{array}$ & $\begin{array}{c}\text { Número } \\
\text { de testes } \\
\text { realizados }\end{array}$ \\
\hline 3,2 & 875,4 & 62,57 & 7,148 & 10 \\
\hline 3,8 & 848,4 & 75,24 & 8,869 & 10 \\
\hline${ }^{*} 4,0$ & 746,7 & 64,34 & 8,616 & 10 \\
\hline${ }^{*} 4,5$ & 524,7 & 84,83 & 13,12 & 10 \\
\hline
\end{tabular}

Tabela 1 - Valores da força máxima de arrancamentos dos parafusos de $5 \mathrm{~mm}$ aplicados nos corpos de prova de madeira e com a perfuração do orifício piloto realizada com brocas.( *) Diferença estatística significativa em relação aos valores da perfuração de $3,8 \mathrm{~mm}$.

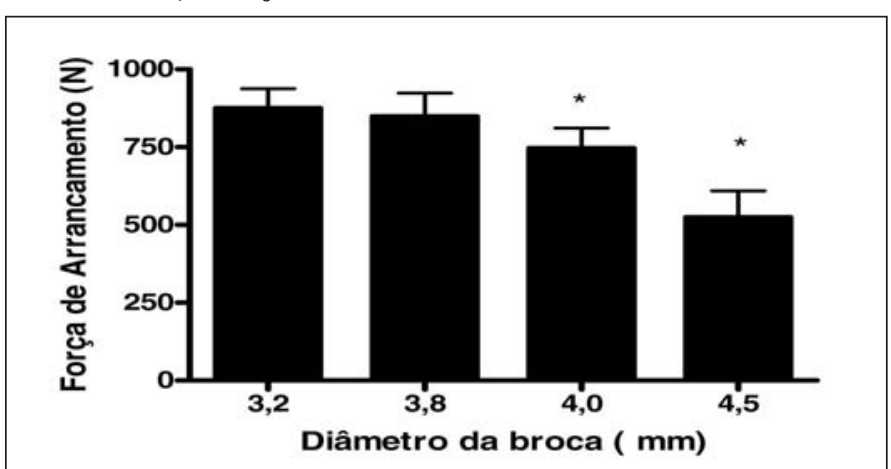

Figura 2 - Os valores da força de arrancamento dos parafusos de $5 \mathrm{~mm}$ e os diferentes diâmetros das brocas utilizadas na perfuração nos corpos de prova de madeira. O asterisco $\left(^{*}\right)$ indica diferença estatística significativa em relação aos valores da perfuração de $3,8 \mathrm{~mm}$.

Os resultados relacionados com a aplicação dos parafusos de $5 \mathrm{~mm}$ nos corpos de prova de poliuretana (Tabela 2 e Figura 3). Foi observado que a média dos valores da força máxima de arrancamento aumentaram com a utilização das brocas com diâmetro inferior ao diâmetro interno do parafuso e decresceram com o aumento do diâmetro da broca em relação ao diâmetro interno do parafuso. Foi observado diferença estatística significativa dos valores da força máxima de arrancamento dos implantes com a utilização de broca de calibre maior ou menor que o diâmetro interno do parafuso.

\begin{tabular}{c|c|c|c|c}
\hline $\begin{array}{c}\text { Diâmetro } \\
\text { da broca } \\
(\mathbf{m m})\end{array}$ & $\begin{array}{c}\text { Força } \\
\text { Máxima } \\
\text { média (N) }\end{array}$ & $\begin{array}{c}\text { Desvio } \\
\text { padrão }\end{array}$ & $\begin{array}{c}\text { Coeficiente } \\
\text { de variação } \\
(\%)\end{array}$ & $\begin{array}{c}\text { Número } \\
\text { de testes } \\
\text { realizados }\end{array}$ \\
\hline${ }^{*} 3,2$ & 50,24 & 3,807 & 7,578 & 10 \\
\hline 3,8 & 30,23 & 2,582 & 8,542 & 10 \\
\hline${ }^{*} 4,5$ & 6,117 & 1,486 & 24,30 & 10 \\
\hline${ }^{*} 4,8$ & 1,181 & 0,325 & 27,53 & 10 \\
\hline
\end{tabular}

Tabela 2 - Valores da força máxima de arrancamentos dos parafusos de $5 \mathrm{~mm}$ aplicados nos corpos de prova de poliuretana e com a perfuração do orifício piloto realizada com brocas. $\left(^{\star}\right)$ Diferença estatística significativa em relação aos valores da perfuração de $3,8 \mathrm{~mm}$. 


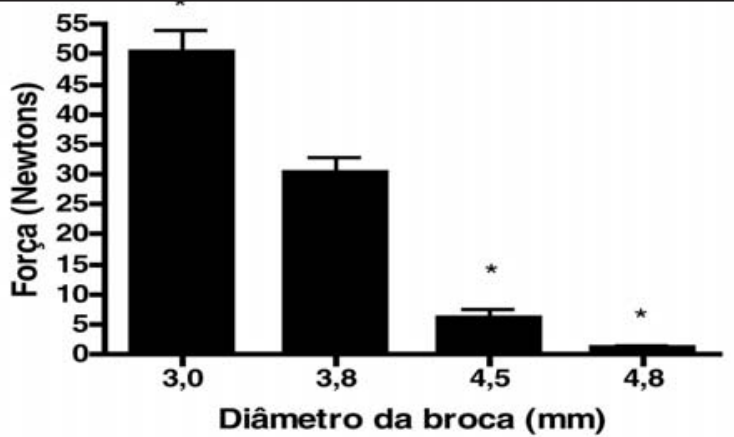

Figura 3 - Os valores da força de arrancamento dos parafusos de $5 \mathrm{~mm}$ aplicados na poliuretana e o com a perfuração realizada com brocas. 0 asterisco $\left(^{*}\right)$ indica diferença estatística significativa em relação aos valores da perfuração de $3,8 \mathrm{~mm}$.

\begin{tabular}{c|c|c|c|c}
\hline $\begin{array}{c}\text { Diâmetro } \\
\text { da broca } \\
(\mathbf{m m})\end{array}$ & $\begin{array}{c}\text { Força } \\
\text { Máxima } \\
\text { média (N) }\end{array}$ & $\begin{array}{c}\text { Desvio } \\
\text { padrão }\end{array}$ & $\begin{array}{c}\text { Coeficiente } \\
\text { de variação } \\
(\mathbf{\%})\end{array}$ & $\begin{array}{c}\text { Número } \\
\text { de testes } \\
\text { realizados }\end{array}$ \\
\hline${ }^{*} 4,0$ & 1047,0 & 95,43 & 9,116 & 10 \\
\hline 4,5 & 935,7 & 92,25 & 9,859 & 10 \\
\hline 4,8 & 868,1 & 66,82 & 7,697 & 10 \\
\hline 5,0 & 809,8 & 65,93 & 8,142 & 10 \\
\hline${ }^{*} 5,5$ & 641,7 & 65,49 & 10,21 & 10 \\
\hline
\end{tabular}

Tabela 3 - Valores da força máxima de arrancamento dos parafusos de $6 \mathrm{~mm}$ aplicados nos corpos de prova de madeira e com a perfuração do orifício piloto realizada com brocas. (*) Diferença estatística significativa em relação aos valores da perfuração de $4,8 \mathrm{~mm}$.

Os resultados relacionados com a utilização do parafuso de 6,0mm nos corpos de prova de madeira (Tabela 3 e Figura 4). Foi observado que a média dos valores da força máxima de arrancamento aumentava à medida que o diâmetro da perfuração decrescia. A diferença foi estatisticamente significativa entre a perfuração de $4,0 \mathrm{~mm}$ de diâmetro e o diâmetro interno do parafuso $(4,8 \mathrm{~mm})$. Apesar de ter sido observado diferença entre os diâmetros de 4,5mm e o diâmetro interno do parafuso, essa diferença não foi estatisticamente significativa. A média da força máxima de arrancamento diminuía à medida que o diâmetro da perfuração aumentava. Foi observada diferença estatística significativa entre a perfuração de 5,5mm e o diâmetro interno do parafuso $(4,8 \mathrm{~mm})$.

Os resultados relacionados com a aplicação dos parafusos de 6,0mm nos corpos de prova de poliuretana (Tabela 4 e Figura 5). Foi observado também a tendência para o aumento da força máxima de arrancamento com a diminuição do diâmetro da perfuração em relação ao diâmetro interno e redução com o seu aumento. No grupo da perfuração com a broca foi observado diferença estatística significativa entre todos os valores da perfuração em relação ao diâmetro interno do implante $(4,8 \mathrm{~mm})$.

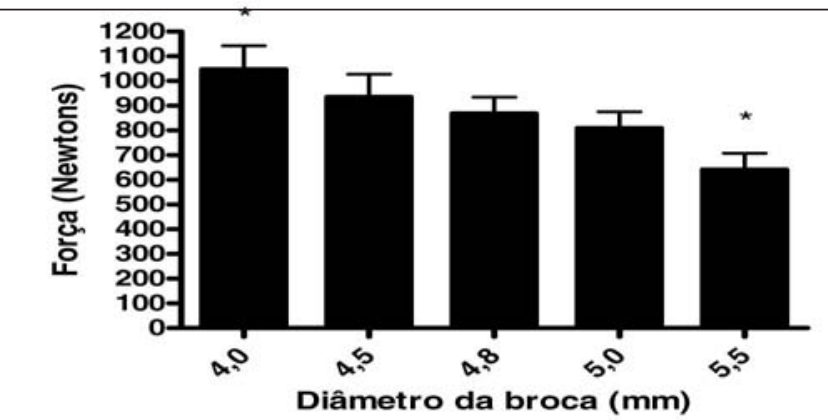

Figura 4 - A força máxima de arrancamento dos parafusos de $6 \mathrm{~mm}$ inseridos nos corpos de prova de madeira e com a perfuração realizada com brocas. $O$ asterisco $\left(^{*}\right)$ indica diferença estatística significativa em relação ao valor do diâmetro interno do parafuso $(4,8 \mathrm{~mm})$

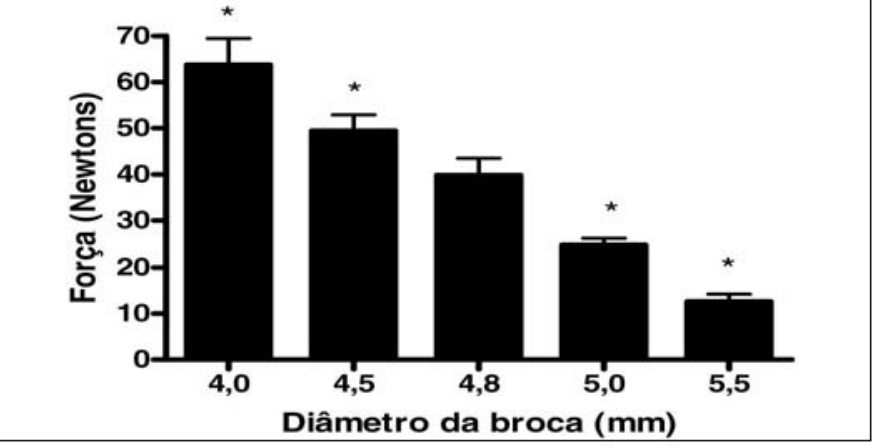

Figura 5 - A força máxima de arrancamento dos parafusos de $6 \mathrm{~mm}$ inseridos na poliuretana e com as perfurações realizadas com brocas. $O$ asterisco $\left(^{*}\right)$ indica diferença estatística significativa em relação ao diâmetro interno do parafuso $(4,8 \mathrm{~mm})$.

\begin{tabular}{c|c|c|c|c}
\hline $\begin{array}{c}\text { Diâmetro } \\
\text { da broca } \\
(\mathbf{m m})\end{array}$ & $\begin{array}{c}\text { Força } \\
\text { Máxima } \\
\text { média (N) }\end{array}$ & $\begin{array}{c}\text { Desvio } \\
\text { padrão }\end{array}$ & $\begin{array}{c}\text { Coeficiente } \\
\text { de variação } \\
(\%)\end{array}$ & $\begin{array}{c}\text { Número } \\
\text { de testes } \\
\text { realizados }\end{array}$ \\
\hline${ }^{*} 4,0$ & 63,71 & 5,724 & 8,984 & 10 \\
\hline${ }^{*} 4,5$ & 49,45 & 3,439 & 6,954 & 10 \\
\hline 4,8 & 39,82 & 3,672 & 9,222 & 10 \\
\hline${ }^{*} 5,0$ & 24,86 & 1,486 & 5,980 & 10 \\
\hline${ }^{*} 5,5$ & 12,65 & 1,572 & 12,43 & 10 \\
\hline
\end{tabular}

Tabela 4 - Valores da força máxima de arrancamento dos parafusos de $6 \mathrm{~mm}$ aplicados nos corpos de prova de poliuretana e com a perfuração do orifício piloto realizada com brocas. $\left(^{*}\right)$ Diferença estatística em relação aos valores da perfuração de $4,8 \mathrm{~mm}$.

Os resultados relacionados com a aplicação dos parafusos de 6,0mm nos corpos de prova de osso bovino (Tabela 5 e Figura 6). Foi observado também a tendência de aumento da força máxima de arrancamento com a diminuição do diâmetro da perfuração em relação ao diâmetro interno e redução com o seu aumento. Foi observada diferença estatística significativa entre todos os valores da perfuração de diâmetro maior ou menos que o diâmetro interno do implante $(4,8 \mathrm{~mm})$.

\begin{tabular}{c|c|c|c|c}
\hline $\begin{array}{c}\text { Diâmetro } \\
\text { da broca } \\
(\mathbf{m m})\end{array}$ & $\begin{array}{c}\text { Força } \\
\text { Máxima } \\
\text { média (N) }\end{array}$ & $\begin{array}{c}\text { Desvio } \\
\text { padrão }\end{array}$ & $\begin{array}{c}\text { Coeficiente } \\
\text { de variação } \\
(\%)\end{array}$ & $\begin{array}{c}\text { Número } \\
\text { de testes } \\
\text { realizados }\end{array}$ \\
\hline${ }^{*} 4,0$ & 786,1 & 146,8 & 18,67 & 10 \\
\hline 4,8 & 504,2 & 145,9 & 28,94 & 10 \\
\hline${ }^{*} 5,5$ & 235,4 & 50,34 & 21,39 & 10 \\
\hline
\end{tabular}

Tabela 5 - Valores da força máxima de arrancamento dos parafusos de $6 \mathrm{~mm}$ aplicados no osso e com a perfuração do orifício piloto realizada com brocas. (*) Diferença estatística significativa em relação aos valores da perfuração de $4,8 \mathrm{~mm}$.

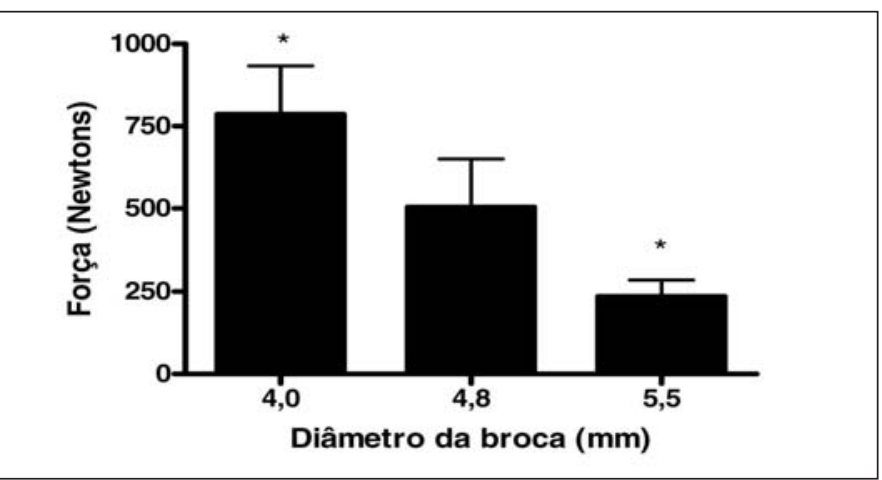

Figura 6 - A força máxima de arrancamento dos parafusos de $6 \mathrm{~mm}$ inseridos no osso e com as perfurações realizadas com brocas. O asterisco (*) indica diferença estatística significativa em relação aos valores da perfuração de 4,8mm. 
Os resultados com a aplicação dos parafusos de 7,0mm nos corpos de prova de madeira (Figura 7 e Tabela 6). Não foi observada diferença estatística significativa do aumento da resistência da força de arrancamento com a redução do diâmetro da broca com relação ao diâmetro interno do parafuso. (perfuração com broca de 4,0 mm). Não foi também observado diferença estatística significativa dos valores da força de arrancamento com o aumento do diâmetro da perfuração para $5,0 \mathrm{~mm}$ e 5,5mm. No entanto os valores relacionados com a perfuração de $6,0 \mathrm{~mm}$ e $6,5 \mathrm{~mm}$ apresentaram diferença estatística significativa com relação ao valor do diâmetro interno do parafuso $(4,8 \mathrm{~mm})$.

Os resultados relacionados com a aplicação dos parafusos de $7,0 \mathrm{~mm}$ nos corpos de prova de poliuretana (Figura 8 e Tabela 7). Foi observada também a tendência de aumento da força máxima de arrancamento com a diminuição do diâmetro da perfuração em relação ao diâmetro interno do parafuso e redução com o seu aumento. Foi observada diferença estatística significativa entre os valores da perfuração de $4 \mathrm{~mm}$ de diâmetro (menor que o diâmetro interno) e todos os valores da perfuração maiores que o diâmetro interno do parafuso (5,0 mm; 5,5mm e 6,6 mm).

\begin{tabular}{c|c|c|c|c}
\hline $\begin{array}{c}\text { Diâmetro } \\
\text { da broca } \\
(\mathbf{m m})\end{array}$ & $\begin{array}{c}\text { Força } \\
\text { Máxima } \\
\text { média (N) }\end{array}$ & $\begin{array}{c}\text { Desvio } \\
\text { padrão }\end{array}$ & $\begin{array}{c}\text { Coeficiente } \\
\text { de variação } \\
(\%)\end{array}$ & $\begin{array}{c}\text { Número } \\
\text { de testes } \\
\text { realizados }\end{array}$ \\
\hline 4,0 & 1134 & 90,23 & 7,954 & 10 \\
\hline 4,8 & 1096 & 84,66 & 7,727 & 10 \\
\hline 5,0 & 1094 & 73,69 & 6,734 & 10 \\
\hline 5,5 & 1004 & 71,05 & 7,079 & 10 \\
\hline${ }^{*} 6,0$ & 890,5 & 94,87 & 10,65 & 10 \\
\hline${ }^{*} 6,5$ & 861,9 & 80,79 & 9,374 & 10 \\
\hline
\end{tabular}

Tabela 6 - Valores da força máxima de arrancamento dos parafusos de $7 \mathrm{~mm}$ aplicados na madeira e com a perfuração do orifício piloto realizada com brocas. (*)Diferença estatística significativa em relação aos valores da perfuração de 4,8mm.

\begin{tabular}{c|c|c|c|c}
\hline $\begin{array}{c}\text { Diâmetro } \\
\text { da broca } \\
(\mathbf{m m})\end{array}$ & $\begin{array}{c}\text { Força } \\
\text { Máxima } \\
\text { média (N) }\end{array}$ & $\begin{array}{c}\text { Desvio } \\
\text { padrão }\end{array}$ & $\begin{array}{c}\text { Coeficiente de } \\
\text { variação }(\%)\end{array}$ & $\begin{array}{c}\text { Número } \\
\text { de testes } \\
\text { realizados }\end{array}$ \\
\hline${ }^{*} 4,0$ & 74,72 & 2,460 & 3,293 & 10 \\
\hline 4,8 & 70,97 & 4,419 & 6,227 & 10 \\
\hline${ }^{*} 5,0$ & 61,56 & 3,570 & 5,800 & 10 \\
\hline${ }^{*} 5,5$ & 43,92 & 3,366 & 7,664 & 10 \\
\hline${ }^{*} 6,5$ & 5,50 & 1,268 & 23,03 & 10 \\
\hline
\end{tabular}

Tabela 7 - Valores da força máxima de arrancamento dos parafusos de $7 \mathrm{~mm}$ aplicados na poliuretana e com a perfuração do orifício piloto realizada com brocas. (*)Diferença estatística em relação aos valores da perfuração de $4,8 \mathrm{~mm}$.

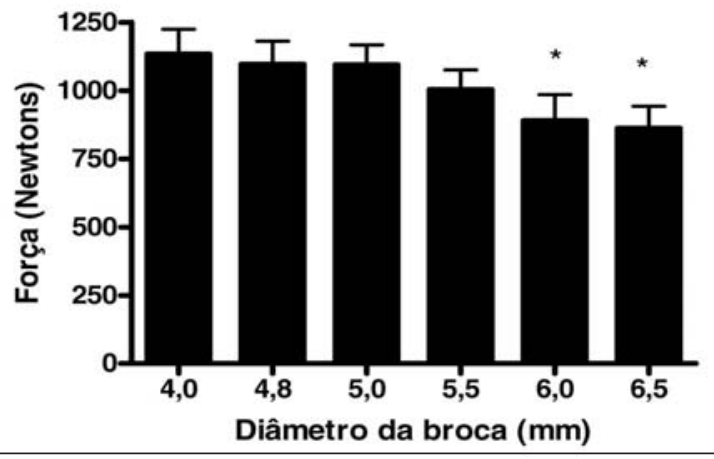

Figura 7 - A força máxima de arrancamento dos parafusos de $7 \mathrm{~mm}$ inseridos na madeira e com as perfurações realizadas com brocas. Oasterisco ${ }^{*}$ ) indica diferença estatística significante em relação ao diâmetro interno do parafuso $(4,8 \mathrm{~mm})$.

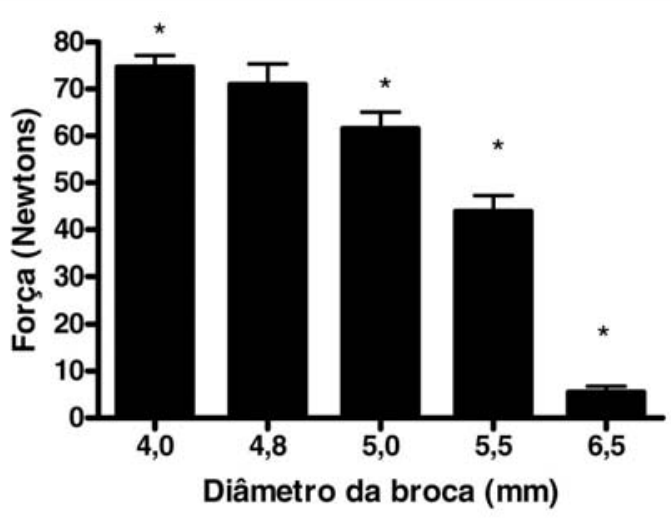

Figura 8 - Os valores da força de arrancamento dos parafusos de $7 \mathrm{~mm}$ aplicados na poliuretana e com a perfuração realizada com brocas. $O$ asterisco (*) indica diferença estatística significativa em relação ao diâmetro interno do parafuso $(4,8 \mathrm{~mm})$.

O resumo dos resultados (Tabela 8) em todos os corpos de prova e diâmetros de parafusos utilizados nos ensaios mecânicos foi possível observar que o diâmetro do orifício piloto foi inversamente proporcional à resistência ao arrancamento dos parafusos, tendo sido observada diferença estatística em todos os valores do orifício piloto acima do diâmetro interno do parafuso. Nos valores do orifício piloto menores que o diâmetro interno foi observada diferença estatística em relação ao diâmetro interno do parafuso nos ensaios realizados nos corpos de prova de poliuretana e osso bovino em todos os diâmetros de parafusos estudados.

\begin{tabular}{|c|c|c|c|c|c|c|c|c|c|c|}
\hline \multirow[b]{2}{*}{ parafuso } & \multirow[b]{2}{*}{ corpo de prova } & \multicolumn{9}{|c|}{ diâmetro da broca (mm) } \\
\hline & & 3,2 & 3,8 & 4 & 4,5 & 4,8 & 5 & 5,5 & 6 & 6,5 \\
\hline \multirow{2}{*}{$5 \mathrm{~mm}$} & madeira & & & * & * & & & & & \\
\hline & poliuretana & * & & * & * & * & & & & \\
\hline & & & & & & & & & & \\
\hline & & & & & & & & & & \\
\hline \multirow{3}{*}{$6 \mathrm{~mm}$} & madeira & & & & & & & * & & \\
\hline & poliuretana & & & * & * & & * & * & & \\
\hline & osso & & & * & & & & * & & \\
\hline \multirow{2}{*}{$7 \mathrm{~mm}$} & madeira & & & & & & & & * & * \\
\hline & poliuretana & & & * & & & & * & & * \\
\hline
\end{tabular}

Tabela 8 - Representação dos diâmetros dos orifícios pilotos, corpos de prova e diâmetro do parafuso utilizado e a indicação da diferença estatística observada nos ensaios de arrancamento dos implantes em relação ao diâmetro interno do parafuso (3,8mm - parafusos de $5 \mathrm{~mm}$ e $4,8 \mathrm{~mm}$ - parafusos de 6 e $7 \mathrm{~mm}$ ). 


\section{DISCUSSÃO}

Os sistemas de fixação vertebral são constituídos por diferentes componentes: componentes de ancoragem (parafusos, ganchos, fios de cerclagem), componetes longitudinais (hastes, placas), conectores transversais e acessórios (arruelas e procas) (2). Os componentes de ancoragem podem ser do tipo penetrante (parafusos) e não penetrantes (ganchos e fios de cerclagem) e atuam como ponto de ancoragem do sistema de fixação nas vértebras, sobre as quais as forças de correção ou neutralização são aplicadas. Desse modo, a ancoragem do parafuso na vértebra é de fundamental importância para o bom desempenho das funções mecânicas do sistema de fixação $\left.0^{(3,5,6}\right)$.

A ancoragem do parafuso na vértebra e a sua resistência mecânica ao arrancamento são influenciadas por vários fatores como a qualidade do tecido ósseo (osteoporose), desenho e diâmetro do implante utilizado e preparo do orifício piloto (diâmetro da perfuração, profundidade e macheamento(3-9).

Os orifício pilotos são realizados para orientar e facilitar a introdução dos parafusos no interior da vértebra, e a sua realização implica na remoção de parte do osso esponjoso da vértebra que é removido com a utilização das brocas de perfuração.A realização do orifício piloto está relacionada com o tipo de osso (cortical ou esponjoso) em que o implante é colocado ${ }^{(2,10)}$.

O osso cortical é mais rígido e a perfuração do orifício piloto de diâmetro menor que o diâmetro interno do parafuso provoca microfraturas no osso adjacente e compromete a qualidade da fixação. Devido a esse fato o orifício piloto é realizado com o diâmetro ligeiramente maior que o diâmetro do parafuso, é utilizado macheamento e os parafusos corticais possuem diâmetro da rosca menor e menor espaço distância entre os passos da rosca e maior diâmetro interno ${ }^{(2,10-12)}$. O stress gerado no osso adjacente ao parafuso do tipo cortical é proporcional ao excesso do diâmetro do implante em relação ao orifício piloto, e não deve exceder a 0,005 para evitar as microfraturas $2,10,12)$

O osso esponjoso possui menor rigidez em relação ao osso cortical e cavidades devido ao arranjo das trabéculas ósseas. A introdução do parafuso no osso esponjoso provoca a compressão do osso adjacente, aumenta a sua densidade e a resistência ao arrancameto do parafuso ${ }^{(2,13)}$. Devido a essas características os parafusos esponjosos possuem rosca de maior tamanho, maior distância entre os passos de rosca e menor diâmetro interno $(2,10)$

$\mathrm{Na}$ coluna vertebral raramente os parafusos pediculares apresentam ancoragem no osso cortical do pedículo e estão em contato com o osso esponjoso do pedículo e corpo vertebral ${ }^{(2,14)}$, desse modo a inserção de parafuso com o diâmetro do orifício piloto menor que o diâmetro interno do parafuso provoca maior compactação do osso esponjoso, e reforça a interface entre o osso e o implante, aumentando a resistência ao arrancamento do implante ${ }^{(12,13)}$. No entanto, o efeito biológico ou biomecânico tardio dessas microfraturas que são produzidas ao redor dos implantes ainda não são conhecidos.

\section{REFERÊNCIAS}

1. Boos N, Webb JK. Pedicle screw fixation in spinal disorders: a European view. Eur Spine J. 1997; 6:2-18

Benzel EC. Biomechanics of spine stabilization. New York: Thieme; 2001.

3. DeCoster TA, Heetkerks DB. Optimizing bone screw pullout force. J Orthop Trauma 1990; 4:169-74

4. Halvorson TL, Kelley LA, Thomas KA, Whitecloud TS 3rd, Cook SD. Effects of bone mineral density on pedicle screw fixation. Spine. 1994; 19:2415-20.

5. Abshire BB, McLain RF, Valdevit A, Kambic HE. Characteristics of pullout failure in conical and cylindrical pedicle screws after full insertion and back-out. Spine J. 2001 1:408-14.

6. George DC, Krag MH, Johnson CC, Van Hal ME, Haugh LD, Grobler LJ. Hole preparation techniques for transpedicle screws. Effect on pull-out strength from human cadaveric vertebrae. Spine. 1991; 16:181-4

7. Abrahão FA, Shimano AC, Defino HLA. Estudo da influência da técnica de preparação dos pedículos vertebrais na resistência ao arrancamento dos implantes. Coluna/ Columna. 2003; 2:111-7.

8. Daftari TK, Horton WC, Hutton WC. Correlations between screw hole preparation, torque of insertion, and pullout strength for spinal screws. J Spinal Disord. 1994; 7:139-45.

9. Barber JW, Boden SD, Ganey T, Hutton WC. Biomechanical study of lumbar pedicle screws: does convergence affect axial pullout strength? J Spinal Disord. 1998

10. Browner BD, Jupiter JB, Levine AM, Trafton PG. Skeletal trauma: basic science, management and reconstruction. 3rd. Philadelphia: Saunders; 2003.
Os resultados observados em nossos ensaios confirmam a hipótese de que a compactação do osso esponjoso ao redor dos parafusos pediculares aumenta a resistência ao arrancamento dos implantes nos diferentes corpos de prova e esses resultados servem de alerta para a consideração do diâmetro do orifício piloto em relação ao diâmetro do implante durante a utilização dessa modalidade de fixação vertebral.

A literatura que aborda esse tema apresenta resultados não concordantes existindo relatos de estudo experimentais nos quais não foi observada a influência do orifício piloto na resistência ao arrancamento, mas da influência do diâmetro da cortical externa ${ }^{(15)}$. Apesar dos inúmeros parâmetros serem mencionados na resistência ao arrancamento dos implantes, não tem sido enfatizado o diâmetro interno do implante ${ }^{(5,15-17)}$.

O modelo experimental utilizado merece algumas considerações pois devido às limitações da utilização de vértebras humanas de densidade homogênea e sem osteoporose foi necessária a utilização de corpos de prova de madeira, poliuretana e osso bovino, seguindo a tendência dos estudos realizados nessa área ${ }^{(3,5,17)}$. A utilização desse tipo de corpos de prova permite a colocação dos parafusos em materiais homogêneos com um padrão de matriz uniforme ${ }^{(17,18)}$.

Os ensaios realizados avaliaram simplesmente a resistência ao arrancamento dos parafusos após a aplicação de força axial, condição que não corresponde àquela da aplicação das cargas fisiológicas cíclicas sobre os implantes, com a aplicação de momentos fletores. No entanto, essa foi a maneira mais simples e prática de estudarmos uma das variáveis relacionadas com a resistência ao arrancamento dos parafusos, que é complexa e está relacionada a muitos fatores diretamente relacionados com a qualidade do tecido ósseo e características dos implantes ${ }^{(2,8)}$. O modo de realização dos ensaios de mecânicos pode afetar os resultados da avaliação da resistência ao arrancamento, e o modo da fixação do corpo de prova e a aplicação da força para a realização do ensaio são variáveis importantes ${ }^{(19)}$. A aplicação da força sobre a ponta dos implantes facilitou a realização dos testes com relação à fixação dos corpos de prova e foi possível contornar os problemas descritos com a realização desse tipo de ensaio(19).

\section{CONCLUSÕES}

A realização do orifício piloto com brocas de diâmetro menor que o diẩmetro interno do parafuso aumentou a força máxima de arrancamento dos implantes nos ensaios mecânicos. Foram observados valores com significância estatística nos corpos de prova de poliuretano e osso.

A realização do orifício piloto com brocas de diâmetro maior que o diâmetro interno do parafuso reduziu a força máxima de arrancamento dos implantes nos ensaios mecânicos. Foi observada significância estatística desse parâmetro nos ensaios realizados nos corpos de prova de madeira, poliuretana e osso.

O diâmetro da perfuração do orifício piloto em relação ao diâmetro interno do parafuso possui influência na resistência ao arrancamento do parafuso.

11. Kwok AW, Finkelstein JA, Woodside T, Hearn TC, Hu RW. Insertional torque and pullout strengths of conical and cylindrical pedicle screws in cadaveric bone. Spine. 1996 21:2429-34.

12. Kuhn A, Mclff T, Cordey J, Baumgart FW, Rahn BA. Bone deformation by thread-cutting and thread-forming cortex screw. Injury. 1995; 26(Suppl 1): SA12-SA20.

13. Oktenoglu BT, Ferrara LA, Andalkar N, Ozer AF, Sarioglu AC, Benzel EC. Effects of hole preparation on screw pullout resistance and insertional torque: a biomechanical study. $J$ Neurosurg. 2006; 94(Suppl 1):91-6.

14. Defino HL, Vendrame JR. Role of cortical and cancellous bone of the vertebral pedicle in implant fixation. Eur Spine J. 2001; 10:325-33.

15. Daftari TK, Horton WC, Hutton WC. Correlations between screw hole preparation, torque of insertion, and pullout strength for spinal screws. J Spinal Disord. 1994; 7:139-45.

16. Carmouche JJ, Molinari RW, Gerlinger T, Devine J, Patience T. Effects of pilot hole preparation technique on pedicle screw fixation in different regions of the osteoporotic thoracic and lumbar spine. J Neurosurg Spine. 2005; 3:364-70.

17. Hsu CC, Chao CK, Wang JL, Hou SM, Tsai YT, Lin J. Increase of pullout strength of spinal pedicle screws with conical core: biomechanical tests and finite element analyses. $J$ Orthop Res. 2005; 23:788-94.

18. Okuyama K, Abe E, Suzuki T, Tamura Y, Chiba M, Sato K. Can insertional torque predict screw loosening and related failures? An in vivo study of pedicle screw fixation augmenting posterior lumbar interbody fusion. Spine. 2000; 25:858-64

19. Pfeiffer M, Gilbertson LG, Goel VK, Griss P, Keller JC, Ryken TC, Hoffman HE. Effect of specimen fixation method on pullout tests of pedicle screws. Spine. 1996; 21:1037-44. 